\title{
Ineffective and prolonged apical contraction is associated with chest pain and ischaemia in apical hypertrophic
}

\section{cardiomyopathy}

Edward Stephenson ${ }^{a}$, Pierre Monney ${ }^{b, c}$, Francesca Pugliese ${ }^{a, b}$, James Malcolmson ${ }^{a, b}$, Steffen E. Petersen ${ }^{a, b}$, Charles Knight ${ }^{a, b}$, Peter Mills ${ }^{b}$, Andrew Wragga,b, Constantinos O’Mahony ${ }^{\mathrm{b}}$, Neha Sekhria,b, Saidi A. Mohiddin ${ }^{\mathrm{a}, \mathrm{b}}$

\begin{abstract}
a William Harvey Research Institute, NIHR Biomedical Research Centre at Barts, Queen Mary University of London, London, United Kingdom

b Barts Heart Centre, Barts Health NHS Trust, London, United Kingdom

c University Hospital of Lausanne (CHUV), Lausanne, Switzerland

Corresponding Author: Dr. S A Mohiddin; saidi.mohiddin@bartshealth.nhs.uk. Address for correspondence: Dr. S A Mohiddin, Department of Cardiology, Barts Heart Centre, 1 St Martins Le Grand, London, EC1A 4AS.
\end{abstract}

Key words: cardiac magnetic resonance; CMR; hypertrophic cardiomyopathy; perfusion 


\section{Abstract}

Objectives: To investigate the hypothesis that persistence of apical contraction into diastole is linked to reduced myocardial perfusion and chest pain.

Background: Apical hypertrophic cardiomyopathy $(\mathrm{HCM})$ is defined by left ventricular (LV) hypertrophy predominantly of the apex. Hyperdynamic contractility resulting in obliteration of the apical cavity is often present. Apical HCM can lead to drug-refractory chest pain.

Methods: We retrospectively studied 126 subjects; 76 with apical HCM and 50 controls (31 with asymmetrical septal hypertrophy (ASH) and 19 with non-cardiac chest pain and culprit free angiograms and structurally normal hearts). Perfusion cardiac magnetic resonance imaging (CMR) scans were assessed for myocardial perfusion reserve index (MPRi), late gadolinium enhancement (LGE), LV volumes (muscle and cavity) and regional contractile persistence (apex, mid and basal LV). Results: In apical HCM, apical MPRi was lower than in normal and ASH controls $(p<0.05)$. In apical HCM, duration of contractile persistence was associated with lower MPRi $(p<0.01)$ and chest pain $(p<0.05)$. In multivariate regression, contractile persistence was independently associated with chest pain $(p<0.01)$ and reduced $\operatorname{MPRi}(p<0.001)$.

Conclusion: In apical HCM, regional contractile persistence is associated with impaired myocardial perfusion and chest pain. As apical myocardium makes limited contributions to stroke volume, apical contractility is also largely ineffective. Interventions to reduce apical contraction and/or muscle mass are potential therapies for improving symptoms without reducing cardiac output. 


\section{Abbreviations}

ASH = asymmetrical septal hypertrophy

$\mathrm{CMR}=$ cardiac magnetic resonance

$E F=$ ejection fraction

FWHM $=$ full width half $\max$

$\mathrm{HCM}=$ hypertrophic cardiomyopathy

LGE = late gadolinium enhancement

$\mathrm{LV}=$ left ventricular

LVH = left ventricular hypertrophy

MPRi $=$ myocardial perfusion reserve index

MWT = maximal wall thickness

PMT = papillary muscles and trabeculae

$\mathrm{RV}=$ right ventricular

SAX $=$ short axis

SSFP = steady state free precession cine

SV = stroke volume

$\% \mathrm{CC}=$ percentage of the cardiac cycle

$\% \mathrm{D}=$ percentage of diastole 


\section{Introduction}

Hypertrophic cardiomyopathy (HCM) is characterised by marked left ventricular (LV) hypertrophy $(\mathrm{LVH})$ [1]. Patients frequently experience troubling chest pain [2-5]. Several studies demonstrate myocardial perfusion abnormalities in HCM [6-10] and others describe biochemical evidence for myocardial ischaemia $[11,12]$. In the absence of coronary disease or LV outflow obstruction, microvascular disease is often assumed to be the cause of myocardial ischaemia. This assumption is based on a few studies that report structural abnormalities of the microvasculature [13-16]. Notably, limited data associates structural changes with perfusion abnormalities or chest pain $[15,17]$.

Myocardial perfusion occurs almost exclusively in diastole and perfusion pressure is greatest in early diastole when suction force due to decompression of the myocardial microcirculation also augments flow [18]. We hypothesised that regional prolongation of systolic contractility into early diastole is associated with reduced myocardial perfusion in $\mathrm{HCM}$.

The aim of this study was to examine associations between chest pain and myocardial perfusion with prolongation of contractility in patients with apical HCM using cardiac magnetic resonance imaging (CMR). 


\section{Methods}

\subsection{Study Design}

This is a retrospective, cross-sectional, observational cohort study based at the London Chest Hospital, UK. Consecutive cases (age $\geq 16$ years) of apical HCM (August 2008-February 2013) were identified from the registry of a regional CMR centre where adenosine stress perfusion imaging was routinely performed in HCM. We also studied control cohorts.

\subsubsection{Apical HCM Cohort}

Morphologic criteria for apical HCM included a maximal end-diastolic LV wall thickness (MWT) $\geq 15 \mathrm{~mm}$ in the apical segments of the heart [1]. We excluded cases where basal septal exceeded apical wall thickness and individuals with left bundle branch block, atrial fibrillation or obstructive coronary disease ( $>50 \%$ narrowing in a major epicardial artery or previous revascularisation). Treated hypertension was not excluded [19]. 


\subsubsection{Control Cohorts}

We identified two control groups:

a). Consecutive patients with the asymmetric septal hypertrophy (ASH) variant of HCM who had also undergone perfusion CMR imaging (control-HCM).

b). Normal controls identified through a low-intermediate risk chest pain pathway in whom coronary angiography and perfusion CMR were performed as part of a prospective research study comparing the diagnostic accuracies of these modalities (EVINCI: NCT00979199) [20]. All normal controls had angiographically normal coronary arteries and structurally normal hearts.

\subsection{Collection of Clinical Data}

Demographic and symptomatic data were collected from electronic records. Chest pain was recorded as present or absent from preceding outpatient clinic letters or scan indication information. Missing data are reported.

\subsection{Consent and Ethical Approval}

This study complies with the declaration of Helsinki and was conducted as audit (Clinical Management of the Inherited and Acquired Heart Muscle Diseases, BartsHealth NHS Trust audit No. 5298). As per protocol, ethics committee approval and informed consent were not sought. 


\subsection{CMR Image Acquisitions and Analysis}

All studies were performed on a 1.5 T magnet (Achieva ${ }^{\circledR}$, Philips Medical Systems) and images acquired using standard protocols, medication was not withheld prior to imaging. Briefly, balanced steady-state free precession cine (SSFP) images were acquired with $25-30$ phases/cardiac cycle $(8 \mathrm{~mm}$ slice thickness, $2 \mathrm{~mm}$ gap for short axis (SAX) images; typical voxel size $1.9 \times 1.9 \mathrm{~mm})$. For perfusion imaging, gadolinium based contrast bolus (Dotarem®) was followed by saline flush. SAX images at basal, mid and apical LV level were obtained at peak stress (adenosine $140 \mu \mathrm{g} / \mathrm{Kg} / \mathrm{min}, 4$ minutes) and at rest. For late gadolinium enhancement (LGE), T1 weighted inversion-recovery gradient echo images were acquired approximately 10 min after gadolinium (typical voxel $2.07 \times 2.16 \mathrm{~mm}$, slice thickness $8 \mathrm{~mm}$, FOV 300 $\mathrm{mm})$.

\subsubsection{Dimensions and Mass}

Endocardial and epicardial borders, including papillary muscles and trabeculae (PMT) within blood pool, were manually traced on SAX images in all cardiac phases (Extended MR Workspace ${ }^{\circledR}$, Philips Medical Systems). Ejection fraction (EF), stroke volume (SV) and LV mass were calculated. Regional (SAX) LV volume was calculated (epicardial - endocardial volume). 


\subsubsection{Measurement of Contractile Persistence}

LV obliteration was measured by manually tracing endocardial and epicardial borders, including PMT within LV muscle volume, for each phase in the three SAX slices co-localising with those for basal, mid-LV and apical perfusion (Figure 1). To standardise the cardiac cycle, data were resampled at 30 phases/cycle if cines were obtained at any different frequency (typically 25-30 phases). LV cavity obliteration was defined as endocardial area $\leq 0.2 \mathrm{~cm}^{2}$ (approximately $1 / 2$ voxel). Diastolic obliteration was that present in any cardiac phase after end-systole. End systole was defined as the phase where total LV volume was lowest (Figure 1A). Contractile persistence duration was expressed as either percentage of the cardiac cycle $(\% \mathrm{CC})$ or diastole $(\% \mathrm{D})$ during which obliteration was present.

\subsubsection{Perfusion Analysis}

The myocardial perfusion reserve index (MPRi) was calculated in basal, mid and apical SAX slices that were not separated into American Heart Association (AHA) segments (without segmentation) [21, 22]. Epicardial, endocardial and blood pool contours were manually traced. After baseline correction, stress and rest signal intensity (SI) time curves were constructed. Maximum upslope was measured using a 4-point window for the myocardium and a 2-point window for the blood pool and mean myocardial maximum upslope was obtained for basal, mid and apical SAX slices, and corrected for arterial input [23]. MPRi was calculated by dividing stress by rest values. 


\subsubsection{Late Gadolinium Enhancement}

Quantity of LGE on T1 weighted images was determined using the full-width half max (FWHM) technique (CMR42, Circle Cardiovascular Imaging Inc., Canada) [24, 25]. The FWHM method was applied to the three SAX slices co-localizing with basal, mid and apex perfusion images and LGE was expressed, without segmentation, as \%myocardium.

\subsubsection{Intra- and Inter-observer Error}

For intra-observer error, MPRi was measured in a random sample of 10 apical HCM twice (with a gap of 1 week), in a random order. For inter-observer error, two independent measurements of MPRi were made in 5 scans, in a random order, by two observers. All patient-identifiable information was removed from the scans and the observers blinded to all other results.

\subsection{Statistical Analysis}

Nominal and parametric baseline characteristics were compared with Chi-squared and paired or unpaired t-tests, respectively. Parametric and non-parametric intergroup differences were tested with one-way ANOVA and Kruskal-Wallis oneway ANOVA tests respectively. Multivariate regression was performed in apical HCM patients to find variables predicting apical MPRi (linear regression) and chest pain (logistic regression). The pre-specified, independent (predictor) variables included sex, age (years), apical LGE (\%LV mass), apical MWT $(\mathrm{mm})$, contractile persistence (\%CC) and MPRi. 
Unless stated, data are presented as mean (SD), p-values are two-tailed and a value of less than 0.05 was considered statistically significant. Where appropriate, Fisher's exact test corrected for small samples and post-hoc Bonferroni correction was used for differences between means. Analyses was performed using StatsDirect, (v2.7.9 (Cheshire, UK)) and STATA (v11). 


\section{Results}

CMR images of sufficient quality were available from 126 subjects (76 apical HCM, $31 \mathrm{ASH}$-controls and 19 normal controls). The baseline characteristics of the cohort are shown in Table 1.

\subsection{Global and Regional LV Morphological Characteristics}

Apical-HCM and control-HCM patients had similar LV end-diastolic and end-systolic volumes (EDV and ESV), LV mass and MWT. EF was marginally greater in apical HCM.

There were differences in regional morphology; apical and mid-LV end-diastolic cavity volumes were lower in apical than in control-HCM but similar at the base. The myocardial volume in the apical SAX slices was greater in apical HCM than control-HCM, but similar in the basal and mid-LV. These data are shown in Table 2.

Resting LV outflow tract obstruction was present in $12(39 \%)$ control-HCM patients. In the $28 \mathrm{HCM}$-control patients where symptom status was available $11(39 \%)$ had resting LVOTO. In this small selected group, differences in the proportions with chest pain were no different in those with resting LVOTO and those without ( 9 of 11 Vs. 11 of 17 respectively; $X^{2} p=0.33$ ). 


\subsection{Cavity Obliteration}

No normal controls demonstrated LV obliteration; the threshold for cavity obliteration was lower than end-systolic apical endocardial area in normal controls $\left(3.3 \pm 1.4 \mathrm{~cm}^{2}\right)$ by 2.2 standard deviations ( $98^{\text {th }}$ percentile).

In apical HCM, LV cavity obliteration was detected in the apex, mid and basal LV in $79 \%, 32 \%$ and $3 \%$ respectively, and in $39 \%, 13 \%$ and $0 \%$ of control-HCM $\left(x^{2}\right.$ $p<0.001$ for apex, $p=0.03$ for mid).

In apical HCM, LV cavity obliteration persisting into diastole was demonstrated in apical, mid and basal LV regions in $78 \%, 26 \%$ and $3 \%$ respectively, and in $26 \%$, $13 \%$ and $0 \%$ of control-HCM ( $x^{2} p<0.001$ for apex $)$.

Cavity obliteration was present for median $32 \% \mathrm{CC}$ in the apex (interquartile range $13 \%-43 \%)$ and $0 \% \mathrm{CC}$ in the mid (0-9\%) in apical $\mathrm{HCM}$; and for $8 \% \mathrm{CC}(0-13 \%)$ and $0 \% \mathrm{CC}(0-0 \%)$, respectively, in control-HCM ( $\mathrm{p}<0.001$ for apex, $\mathrm{p}<0.05$ for mid). When only diastolic cavity obliteration was assessed, this was for $33 \% \mathrm{D}$ at the apex $(12-44 \%)$ and $0 \% \mathrm{D}$ in the mid $(0-9 \%)$ in apical HCM and $12 \% \mathrm{D}(0-13 \%)$ and $0 \% \mathrm{D}(0-$ $0 \%)$, respectively, in control-HCM ( $p<0.001$ for apex). 


\subsection{Regional Myocardial Perfusion}

MPRi at the apex in apical HCM $(1.1 \pm 0.3)$ was lower than that in control-HCM $(1.5 \pm 0.6 ; p<0.001)$ and normal controls $(1.6 \pm 0.5 ; p<0.001)$. MPRi in the basal and mid LV were similar in apical and control-HCM groups (Table 2). In apical HCM, MPRi was lower in the apex than the base $(1.1 \pm 0.3$ and $1.3 \pm 0.4$ respectively; p<0.001). MPRi was also lower, in apical HCM, at the apex compared to the mid-LV $(1.1 \pm 0.3$ and $1.2 \pm 0.5$ respectively; $p=0.03)$. MPRi at all three levels were similar in control-HCM and in normal controls.

\subsection{Global and Regional Late Gadolinium Enhancement}

Globally, \%LGE in apical and control-HCM was similar. Regionally, in apical HCM, $\%$ LGE in the apex $(7.3 \pm 8.0 \%)$ was greater than in the base $(4.7 \pm 5.7 \%, p=0.007)$ and greater than in the apex of control-HCM $(1.9 \pm 3.7 \% ; p=0.002)$. There was a significant univariate association between \%LGE and MWT in the apex of apical $\operatorname{HCM}(\rho=0.40, p<0.001)$.

\subsection{Apical HCM}

\subsubsection{Chest Pain and Myocardial Perfusion}

To examine for associations between perfusion or chest pain with morphologic and functional abnormalities, we divided apical HCM into tertiles for LVH magnitude (MWT) and apical contractile persistence (Table 3). 


\subsubsection{Magnitude of LVH}

MWT tertiles had similar chest pain prevalence and regional apical MPRi (Table 3). \%LGE was greatest in the highest MWT tertile; for all patients, there was a significant univariate correlation between MWT and \%LGE $(r=0.36, p=0.001)$, but not with MPRi (Table 4).

\subsubsection{Duration of Apical Cavity Obliteration}

Apical obliteration persisted through a median of 50\%D (interquartile range $44 \%$ $55 \%)$ in the group with most obliteration (CIII), 33\%D (29-37\%) and 0\%D (0-12\%) in intermediate $(\mathrm{CII})$ and least severe groups $(\mathrm{Cl})$ respectively. Most measures of global LV structure/function and \%LGE were similar.

Chest pain was much more frequently reported in CIII ( $22 p<0.05$; Table 3). Apical MPRi was lower in CIII patients than $\mathrm{Cl}(p<0.001)$ and $\mathrm{CII}(\mathrm{p}=0.007)$. For all apical HCM, both \%D (r=-0.52, $\left.r^{2}=0.27, p<0.001\right)$ and \%CC $\left(r=-0.54, r^{2}=0.29, p<0.001\right)$ correlated with MPRi (Table 4, Figure 2A).

\subsection{Multivariate Analyses}

Duration of contractile persistence, \%CC, was independently associated with chest pain $(p<0.005)$ and a reduction in apical MPRi $(p<0.001)($ Table 4). Analyses for contractile persistence as \%D were similar (data not shown). 


\subsection{Inter- and Intra-observer Error}

For the three areas of the left ventricle in 20 patients $(n=60)$, the intra-observer mean difference in MPRi was $-0.02(95 \% \mathrm{Cl} ;-0.10$ to $0.041, \mathrm{p}=0.52)$. The inter-observer mean difference in MPRi for 5 patients $(n=15)$ was $-0.07(95 \% \mathrm{Cl} ;-0.19$ to 0.04 , $p=0.18)$. 


\section{Discussion}

This study shows for the first time that chest pain in apical HCM is associated with distinct contractile abnormalities. Our novel finding is that the persistence of apical contraction is strongly associated with chest pain and regional impairment in myocardial perfusion. We suggest that apical muscle exhibits pathological contractility into diastole, resulting in ischaemia and symptoms.

In comparison to other morphologic variants, apical HCM has a relatively benign prognosis in both Western and Asian populations [26, 27]. Reported prevalence of chest pain in patients with apical HCM cared for at tertiary centres varies widely between 30 and $92 \%$ and is frequently refractory to pharmacological therapy [26-32]. Chest pain is commonly attributed to myocardial ischaemia, the cause of which is not well understood and several mechanisms including microvascular dysfunction, reduced capillary density and myocardial bridging have been implicated [33-35].

Early diastole is particularly important for myocardial perfusion [18]. We hypothesised that regional differences in persistence of early diastolic contractility could result in impaired myocardial perfusion in $\mathrm{HCM}$. In order to examine this hypothesis, we used CMR to assess regional contractility and MPRi in apical HCM and used two comparator cohorts to investigate morphologic and contractile abnormalities particular to apical HCM. Notably, despite similar disease severity (including LV mass, max wall thickness and \%LGE), LV cavity obliteration, a common feature of apical HCM, was considerably less frequently detected in ASH$\mathrm{HCM}$, and was much less persistent when present. Cavity obliteration was not detected in normal controls. 
The pathophysiology of chest pain in HCM is complex. In this study of apical HCM, almost all patients with contractile systolic persistence of $>40 \%$ of cardiac cycle and/or MPRi $<1$ experienced chest pain (Figure 2B). However, chest pain was also present in the absence of these two abnormalities in a substantial subgroup of patients, suggesting that other factors are contributing. Similarly, low MPRi is not always associated with contractile systolic persistence of $>40 \%$, suggesting that additional factors are at play [6, 36-38].

\subsection{Implications for other HCM Variants}

In apical HCM, cavity obliteration is easily detectable and quantifiable. Post-systolic regional contractile persistence in other variants/myocardial regions may be less readily discerned. For example, in patients with $\mathrm{ASH}$, an AHA-segmental rather than regional analysis of $L V$ contraction would be required to demonstrate this phenomenon in the basal septum. Analyses of differences in regional strain may help determine if this mechanism contributes to symptoms in other HCM variants, and in other cardiac conditions. 


\subsection{Therapeutic Implications}

Our hypothesis is consistent with the efficacy of conventional drug therapies for symptomatic HCM that decrease contractility, prolong diastole and promote lusitropy. For drug-refractory chest pain, invasive options are only considered when there is dynamic LV obstruction [1]; such symptoms can be exceptionally difficult to manage in non-obstructive $\mathrm{HCM}$. We present very preliminary evidence that therapies which manipulate contraction/relaxation on a global (with investigative molecules such as MYK-461/Mavacamten) or a regional basis (such as RV or LV pacing) may warrant further investigation in severely symptomatic apical $\operatorname{HCM}[31,39,40]$. These investigations should be advanced in rigorous peer-reviewed prospective research settings. Notably, the regional reduction of muscle mass (surgical and non-surgical myectomy) that has been advocated for some patients with severe forms of apical HCM may, in part, improve chest pain by interrupting this mechanism [30, 41].

\subsection{Limitations}

This single centre study retrospectively selects $\mathrm{HCM}$ patients that have undergone stress CMR. Stress CMR imaging is a routine component of our clinical evaluation of all HCM patients in the absence of contra-indications. In addition, several subjects scanned in our centre are managed in other centres, limiting available data and contributing to selection bias. This also meant we were unable to index our CMR findings to body surface area. There was a non-significant trend for apical HCM patients with more severe disease, in terms of apical contractile persistence, to be more likely to be treated with a beta-blocker and/or calcium channel antagonist. Differences in medical therapy may have affected LV contraction, but these are more likely to obscure a relationship between contractility and symptoms. 
A prospective study would include long-axis perfusion imaging to account for longaxis systolic function, as well as more specialised quantitative perfusion techniques (for example by using a dual-bolus approach to assess myocardial blood flow (MBF)). Tissue tagging could provide additional data on regional differences in contraction and relaxation. Finally, hypercontractility would be assessed on images obtained during stress. A prospective study could also include invasive perfusion pressure and volume measurements to further substantiate our observations.

\section{Conclusions}

In conclusion, duration of systolic cavity obliteration is associated with chest pain and impaired myocardial perfusion in apical HCM. We speculate that the prolongation of systolic contraction into diastole impairs myocardial blood flow to cause regional myocardial ischaemia. 
Acknowledgements:

FP and SEP acknowledge the National Institute for Health Research (NIHR)

Cardiovascular Biomedical Research Unit at Barts. FP has received grant support from Siemens Healthcare. 


\section{References}

[1] Elliott PM, Anastasakis A, Borger MA, Borggrefe M, Cecchi F, Charron P, et al. 2014 ESC Guidelines on diagnosis and management of hypertrophic cardiomyopathy: The Task Force for the Diagnosis and Management of Hypertrophic Cardiomyopathy of the European Society of Cardiology (ESC). European heart journal. 2014.

[2] Elliott PM, Gimeno JR, Thaman R, Shah J, Ward D, Dickie S, et al. Historical trends in reported survival rates in patients with hypertrophic cardiomyopathy. Heart. 2006;92:785-91.

[3] Ho HH, Lee KL, Lau CP, Tse HF. Clinical characteristics of and long-term outcome in Chinese patients with hypertrophic cardiomyopathy. The American journal of medicine. 2004;116:19-23.

[4] Fernandez A, Vigliano CA, Casabe JH, Diez M, Favaloro LE, Guevara E, et al. Comparison of prevalence, clinical course, and pathological findings of left ventricular systolic impairment versus normal systolic function in patients with hypertrophic cardiomyopathy. The American journal of cardiology. 2011;108:548-55.

[5] Kubo T, Kitaoka H, Okawa M, Hirota T, Hayato K, Yamasaki N, et al. Gender-specific differences in the clinical features of hypertrophic cardiomyopathy in a community-based Japanese population: results from Kochi RYOMA study. Journal of cardiology. 2010;56:314-9.

[6] Matsunaka T, Hamada M, Matsumoto Y, Higaki J. First-pass myocardial perfusion defect and delayed contrast enhancement in hypertrophic cardiomyopathy assessed with MRI. Magnetic resonance in medical sciences : MRMS : an official journal of Japan Society of Magnetic Resonance in Medicine. 2003;2:61-9.

[7] Sugihara H, Taniguchi Y, Ito K, Terada K, Matsumoto K, Kinoshita N, et al. Effects of diltiazem on myocardial perfusion abnormalities during exercise in patients with hypertrophic cardiomyopathy. Annals of nuclear medicine. 1998;12:349-54.

[8] Mori T, Yamabe H, Yokota Y, Fukuzaki H. Clinical significance of dipyridamole Tl-201 emission computed tomography perfusion abnormality for evaluating pathophysiological and pathological aspects in hypertrophic cardiomyopathy. Japanese circulation journal. 1988;52:111-8.

[9] Moon J, Cho IJ, Shim CY, Ha JW, Jang Y, Chung N, et al. Abnormal myocardial capillary density in apical hypertrophic cardiomyopathy can be assessed by myocardial contrast echocardiography. Circulation journal : official journal of the Japanese Circulation Society. 2010;74:2166-72.

[10] Petersen SE, Jerosch-Herold M, Hudsmith LE, Robson MD, Francis JM, Doll HA, et al. Evidence for microvascular dysfunction in hypertrophic cardiomyopathy: new insights from multiparametric magnetic resonance imaging. Circulation. 2007;115:2418-25.

[11] Cannon RO, 3rd, Schenke WH, Maron BJ, Tracy CM, Leon MB, Brush JE, Jr., et al. Differences in coronary flow and myocardial metabolism at rest and during pacing between patients with obstructive and patients with nonobstructive hypertrophic cardiomyopathy. Journal of the American College of Cardiology. 1987;10:53-62.

[12] Cannon RO, 3rd, McIntosh CL, Schenke WH, Maron BJ, Bonow RO, Epstein SE. Effect of surgical reduction of left ventricular outflow obstruction on hemodynamics, coronary flow, and myocardial metabolism in hypertrophic cardiomyopathy. Circulation. 1989;79:766-75.

[13] Kofflard MJ, Michels M, Krams R, Kliffen M, Geleijnse ML, Ten Cate FJ, et al. Coronary flow reserve in hypertrophic cardiomyopathy: relation with microvascular dysfunction and pathophysiological characteristics. Netherlands heart journal : monthly journal of the Netherlands Society of Cardiology and the Netherlands Heart Foundation. 2007;15:209-15.

[14] Takemura G, Takatsu Y, Fujiwara H. Luminal narrowing of coronary capillaries in human hypertrophic hearts: an ultrastructural morphometrical study using endomyocardial biopsy specimens. Heart. 1998;79:78-85 .

[15] Krams R, Kofflard MJ, Duncker DJ, Von Birgelen C, Carlier S, Kliffen M, et al. Decreased coronary flow reserve in hypertrophic cardiomyopathy is related to remodeling of the coronary microcirculation. Circulation. 1998;97:230-3.

[16] Johansson B, Morner S, Waldenstrom A, Stal P. Myocardial capillary supply is limited in hypertrophic cardiomyopathy: a morphological analysis. International journal of cardiology. 2008;126:252-7.

[17] Schwartzkopff B, Mundhenke M, Strauer BE. Alterations of the architecture of subendocardial arterioles in patients with hypertrophic cardiomyopathy and impaired coronary vasodilator reserve: a possible cause for myocardial ischemia. Journal of the American College of Cardiology. 1998;31:1089-96.

[18] Davies JE, Whinnett ZI, Francis DP, Manisty CH, Aguado-Sierra J, Willson K, et al. Evidence of a dominant backward-propagating "suction" wave responsible for diastolic coronary filling in humans, attenuated in left ventricular hypertrophy. Circulation. 2006;113:1768-78.

[19] Shapiro LM. Hypertrophic cardiomyopathy in the elderly. British heart journal. 1990;63:265-6.

[20] Neglia D, Rovai D, Caselli C, Pietila M, Teresinska A, Aguade-Bruix S, et al. Detection of significant coronary artery disease by noninvasive anatomical and functional imaging. Circulation Cardiovascular imaging. 2015;8. 
[21] Chih S, Macdonald PS, Feneley MP, Law M, Graham RM, McCrohon JA. Reproducibility of adenosine stress cardiovascular magnetic resonance in multi-vessel symptomatic coronary artery disease. Journal of cardiovascular magnetic resonance : official journal of the Society for Cardiovascular Magnetic Resonance. 2010;12:42.

[22] Al-Saadi N, Nagel E, Gross M, Bornstedt A, Schnackenburg B, Klein C, et al. Noninvasive detection of myocardial ischemia from perfusion reserve based on cardiovascular magnetic resonance. Circulation. 2000;101:1379-83.

[23] Wong DT, Leung MC, Das R, Liew GY, Williams K, Dundon BK, et al. Diagnostic accuracy of adenosine stress cardiovascular magnetic resonance following acute ST-segment elevation myocardial infarction post primary angioplasty. Journal of cardiovascular magnetic resonance : official journal of the Society for Cardiovascular Magnetic Resonance. 2011;13:62.

[24] Flett AS, Hasleton J, Cook C, Hausenloy D, Quarta G, Ariti C, et al. Evaluation of techniques for the quantification of myocardial scar of differing etiology using cardiac magnetic resonance. JACC Cardiovascular imaging. 2011;4:150-6.

[25] Beek AM, Bondarenko O, Afsharzada F, van Rossum AC. Quantification of late gadolinium enhanced CMR in viability assessment in chronic ischemic heart disease: a comparison to functional outcome. Journal of cardiovascular magnetic resonance : official journal of the Society for Cardiovascular Magnetic Resonance. 2009;11:6.

[26] Eriksson MJ, Sonnenberg B, Woo A, Rakowski P, Parker TG, Wigle ED, et al. Long-term outcome in patients with apical hypertrophic cardiomyopathy. J Am Coll Cardiol. 2002;39:638-45.

[27] Yan L, Wang Z, Xu Z, Li Y, Tao Y, Fan C. Two hundred eight patients with apical hypertrophic cardiomyopathy in china: clinical feature, prognosis, and comparison of pure and mixed forms. Clin Cardiol. 2012;35:101-6.

[28] Sorajja P, Nishimura RA, Gersh BJ, Dearani JA, Hodge DO, Wiste HJ, et al. Outcome of mildly symptomatic or asymptomatic obstructive hypertrophic cardiomyopathy: a long-term follow-up study. Journal of the American College of Cardiology. 2009;54:234-41.

[29] Kitaoka H, Kubo T, Hayashi K, Yamasaki N, Matsumura Y, Furuno T, et al. Tissue Doppler imaging and prognosis in asymptomatic or mildly symptomatic patients with hypertrophic cardiomyopathy. European heart journal cardiovascular Imaging. 2013;14:544-9.

[30] Angelini P, Uribe C, Monge J, Escobar JM, Hernandez-Vila E. Apical hypertrophic cardiomyopathy: preliminary attempt at palliation with use of subselective alcohol ablation. Tex Heart Inst J. 2012;39:750-5.

[31] Wever-Pinzon O, Romero J, Cordova JP. Dual chamber pacing relieves obstruction in Japanese-variant hypertrophic cardiomyopathy. American journal of therapeutics. 2013;20:588-90.

[32] Yang HS, Song JK, Song JM, Kang DH, Lee CW, Hong MK, et al. Comparison of the clinical features of apical hypertrophic cardiomyopathy versus asymmetric septal hypertrophy in Korea. Korean J Intern Med. 2005;20:111-5.

[33] Bravo PE, Pinheiro A, Higuchi T, Rischpler C, Merrill J, Santaularia-Tomas M, et al. PET/CT assessment of symptomatic individuals with obstructive and nonobstructive hypertrophic cardiomyopathy. Journal of nuclear medicine : official publication, Society of Nuclear Medicine. 2012;53:407-14.

[34] Knaapen P, Germans T, Camici PG, Rimoldi OE, ten Cate FJ, ten Berg JM, et al. Determinants of coronary microvascular dysfunction in symptomatic hypertrophic cardiomyopathy. American journal of physiology Heart and circulatory physiology. 2008;294:H986-93.

[35] Mohiddin SA, Begley D, Shih J, Fananapazir L. Myocardial bridging does not predict sudden death in children with hypertrophic cardiomyopathy but is associated with more severe cardiac disease. Journal of the American College of Cardiology. 2000;36:2270-8.

[36] Chiribiri A, Leuzzi S, Conte MR, Bongioanni S, Bratis K, Olivotti L, et al. Rest perfusion abnormalities in hypertrophic cardiomyopathy: correlation with myocardial fibrosis and risk factors for sudden cardiac death. Clinical radiology. 2015;70:495-501.

[37] Peteiro J, Fernandez X, Bouzas-Mosquera A, Monserrat L, Mendez C, Rodriguez-Garcia E, et al. Exercise echocardiography and cardiac magnetic resonance imaging to predict outcome in patients with hypertrophic cardiomyopathy. European heart journal cardiovascular Imaging. 2015;16:423-32.

[38] Bernhardt P, Levenson B, Albrecht A, Engels T, Strohm O. Detection of cardiac small vessel disease by adenosine-stress magnetic resonance. International journal of cardiology. 2007;121:261-6.

[39] Green EM, Wakimoto H, Anderson RL, Evanchik MJ, Gorham JM, Harrison BC, et al. A small-molecule inhibitor of sarcomere contractility suppresses hypertrophic cardiomyopathy in mice. Science. 2016;351:61721. 
[40] Stern JA, Markova S, Ueda Y, Kim JB, Pascoe PJ, Evanchik MJ, et al. A Small Molecule Inhibitor of Sarcomere Contractility Acutely Relieves Left Ventricular Outflow Tract Obstruction in Feline Hypertrophic Cardiomyopathy. PLoS One. 2016;11:e0168407.

[41] Schaff HV, Brown ML, Dearani JA, Abel MD, Ommen SR, Sorajja P, et al. Apical myectomy: a new surgical technique for management of severely symptomatic patients with apical hypertrophic cardiomyopathy. J Thorac Cardiovasc Surg. 2010;139:634-40. 


\section{Figure Legends}

Figure 1: Contractile persistence in three subjects. Columns from left to right: long axis CMR images at end-diastole and end-systole respectively; typical endocardial area changes across the cardiac cycle, and; basal, mid and apical MPRi. Row (A) Apical HCM, (B) ASHHCM, (C) Normal control.

Figure 2: Panel A: Scatter plot demonstrating relation of MPRi and contractile persistence (\%CC) in 76 apical HCM patients. As persistence increases, myocardial perfusion declines. The linear regression line and $95 \% \mathrm{Cl}$ are shown $(\mathrm{MPRi}=1.40-0.0092 \% \mathrm{CC} ; 95 \% \mathrm{Cl}$ of coefficient: -0.01 to $-0.006 ; p<0.001)$. Panel B: Scatter plot demonstrating relation of MPRi and contractile persistence $(\% \mathrm{CC})$ in 66 apical HCM patients: 47 with (red markers) and 19 without chest pain (blue markers) (chest pain data missing from 10 apical HCM patients). Almost all patients with contractile persistence $>40 \%$ of cardiac cycle and/or MPRi $<1$ had chest pain (MPRi=1.39 $-0.0088 * \% C C ; 95 \% \mathrm{Cl}$ of coefficient: -0.01 to $-0.005 ; p<0.001)$. Panels C and D: Box plots of contractile persistence (\%CC) and MPRi according to chest pain status $\left({ }^{*}: p<0.05,{ }^{* * *}: p<0.001\right)$. 
Table 1: Baseline characteristics

\begin{tabular}{|c|c|c|c|}
\hline & $\begin{array}{l}\text { Apical HCM } \\
(n=76)\end{array}$ & $\begin{array}{c}\text { ASH-HCM } \\
(n=31)\end{array}$ & $\begin{array}{c}\text { Normal } \\
\text { controls } \\
(n=19)\end{array}$ \\
\hline Male, n (\%) & $47(62)$ & $23(74)$ & $14(74)$ \\
\hline Age at scan, average (SD) & $58.6(13)$ & $62.0(13)$ * & $51.7(11)$ \\
\hline \multicolumn{4}{|l|}{ Ethnicity } \\
\hline Information available $(\mathrm{n})$ & 67 & 26 & 16 \\
\hline White, $\mathrm{n}(\%)$ & $16(24)$ & $9(35)$ & $6(38)$ \\
\hline Asian, n (\%) & $32(48)$ & $10(39)$ & $6(38)$ \\
\hline Black, n (\%) & 13 (19) & $6(23)$ & $4(25)$ \\
\hline Mixed, n (\%) & $6(9)$ & $1(4)$ & $0(0)$ \\
\hline \multicolumn{4}{|l|}{ Treated Hypertension } \\
\hline Information available $(\mathrm{n})$ & 68 & 28 & 19 \\
\hline Present, n (\%) & $50(74) \dagger$ & $22(79) \dagger$ & $8(42)$ \\
\hline \multicolumn{4}{|l|}{ NYHA function class } \\
\hline Information available (n) & 64 & 27 & \\
\hline $1, \mathrm{n}(\%)$ & $36(56)$ & $10(37)$ & \\
\hline $2, \mathrm{n}(\%)$ & $16(25)$ & $12(44)$ & \\
\hline $3, \mathrm{n}(\%)$ & $12(19)$ & $5(19)$ & \\
\hline \multicolumn{4}{|l|}{ Chest pain } \\
\hline Information available (n) & 66 & 28 & \\
\hline Present, $\mathrm{n}(\%)$ & $47(71)$ & $20(71)$ & \\
\hline
\end{tabular}

*: $p<0.05$ vs. Normal controls; $\uparrow: x 2 p<0.05$ 


\begin{tabular}{|c|c|c|c|}
\hline & $\begin{array}{c}\text { Apical HCM } \\
(n=76)\end{array}$ & $\begin{array}{c}\text { ASH-HCM } \\
(n=31)\end{array}$ & $\begin{array}{c}\text { Normal controls } \\
(n=19)\end{array}$ \\
\hline LV EDV (mL) & $115(29)$ & $122(33)$ & $129(34)$ \\
\hline $\begin{array}{l}\text { LV ESV (mL) } \\
\text { EF (\%) }\end{array}$ & $\begin{array}{l}38(17)^{*} \\
68(8)^{* *} \dagger\end{array}$ & $\begin{array}{l}47(23) \\
63(10)\end{array}$ & $\begin{array}{l}51(22) \\
61(8)\end{array}$ \\
\hline ED MWT (mm) & $18.8(3.4)^{* * *}$ & $18.3(2.5)^{* * *}$ & $10.1(2.0)$ \\
\hline $\begin{array}{l}\text { LV mass }(\mathrm{g}) \\
\text { Endocardial area }\left(\mathrm{cm}^{2}\right)\end{array}$ & $177(64)^{* \star *}$ & $155(42) * * *$ & $100(33)$ \\
\hline $\begin{array}{ll}\text { Base } \\
\text { Mid } \\
\text { Apex }\end{array}$ & $\begin{array}{c}15.1(5.4)^{* *} \\
9.3(3.6)^{* * *}+\dagger \dagger \\
4.4(2.4)^{* * *}+\dagger \dagger\end{array}$ & $\begin{array}{l}15.5(4.2)^{* *} \\
12.9(4.6)^{* * *} \\
8.7(3.9)^{* * *}\end{array}$ & $\begin{array}{l}19.9(4.4) \\
17.9(3.2) \\
12.8(3.2)\end{array}$ \\
\hline Myocardial area $\left(\mathrm{cm}^{2}\right)$ & & & \\
\hline $\begin{array}{ll}\text { Base } \\
\text { Mid } \\
\text { Apex }\end{array}$ & $\begin{array}{l}27.0(6.7)^{* * *} \\
27.0(6.8)^{* * *} \\
21.2(7.8)^{* *}+\dagger\end{array}$ & $\begin{array}{l}26.5(7.4)^{* * *} \\
24.2(7.2)^{* * *} \\
16.8(6.4)^{* *}\end{array}$ & $\begin{array}{l}18.7(5.5) \\
16.0(4.7) \\
11.0(3.3)\end{array}$ \\
\hline $\begin{array}{l}\text { Base } \\
\text { Mid } \\
\text { Apex }\end{array}$ & $\begin{array}{c}1.3(0.4) \neq \ddagger \ddagger \\
1.2(0.5) \ddagger \\
1.1(0.3)^{* * *} \dagger \dagger \dagger\end{array}$ & $\begin{array}{l}1.4(0.6) \\
1.5(0.6) \\
1.5(0.6)\end{array}$ & $\begin{array}{l}1.5(0.5) \\
1.5(0.4) \\
1.6(0.5)\end{array}$ \\
\hline
\end{tabular}

All data presented as mean (SD). ${ }^{*}: p<0.05,{ }^{* *}: p<0.01,{ }^{* * *}: p<0.001$ vs. normal controls; $\dagger: p<0.05$, †††: $p<0.001$ vs. ASH-HCM; $\ddagger: p<0.05, \ddagger \ddagger \ddagger: p<0.001$ vs. Apical HCM apex. 
Table 3: Differences between apical HCM patients divided into tertiles on the basis of LVH and apical contractile persistence (tertile 1 best $(n=26), 2(n=25)$, tertile 3 worst $(n=25)$, and for gender ( male=47, female=29)

\begin{tabular}{|c|c|c|c|c|c|c|c|c|}
\hline & \multicolumn{3}{|c|}{ Apical MWT } & \multicolumn{3}{|c|}{ Contractile Persistence, $\%$ cardiac cycle } & \multicolumn{2}{|c|}{ Gender } \\
\hline & 1 & 2 & 3 & 1 & 2 & 3 & Male & Female \\
\hline $\begin{array}{l}\text { Range } \\
\text { (mean) }\end{array}$ & $\begin{array}{l}15-16 \\
(15.4)\end{array}$ & $\begin{array}{l}16-20 \\
(18.2)\end{array}$ & $\begin{array}{l}21-28 \\
(23.0)\end{array}$ & $\begin{array}{c}0-20 \\
(6)\end{array}$ & $\begin{array}{c}23-37 \\
(32)\end{array}$ & $\begin{array}{c}40-73 \\
(49)\end{array}$ & & \\
\hline Male, $\mathrm{n}(\%)$ & $14(54)$ & $14(56)$ & $19(73)$ & $18(69)$ & $16(64)$ & $13(52)$ & & \\
\hline Age (SD), years & $62(14)$ & 59 (13) & 56 (13) & $58(13)$ & 59 (13) & 59 (14) & $56(13) \S$ & $63(13)$ \\
\hline Chest pain, $\mathrm{n}(\%)$ & $16(70)$ & $14(63)$ & $17(78)$ & $13(57)$ & $15(68)$ & $19(91)$ * & $31(76)$ & $16(64)$ \\
\hline \multirow{4}{*}{$\begin{array}{l}\text { Apex MWT (SD), mm } \\
\text { LV apical LGE (SD), \% } \\
\text { Apex contractile persistence }\end{array}$} & & & & $17.9(3.0)$ & $18.9(3.3)$ & 19.8 (3.8) & $19.5(3.6) \S$ & $17.7(2.8)$ \\
\hline & $5.4(7.7) \dagger$ & $5.5(6.9) \dagger$ & $11.0(8.3)$ & $7(8)$ & $6(8)$ & $9(8)$ & $9.0(8.6) \S$ & $4.5(6.0)$ \\
\hline & $24(18)$ & $30(20)$ & $32(20)$ & & & & $26(20)$ & $33(18)$ \\
\hline & $21(18)$ & $26(19)$ & $29(19)$ & 4 (7) ††† 㧊 & $28(6) \dagger \dagger \dagger$ & $45(13)$ & $23(19)$ & $29(18)$ \\
\hline Apical MPRi (SD) & $1.1(0.4)$ & $1.2(0.3)$ & $1.0(0.3)$ & $1.3(0.3)$ ††† & $1.2(0.3) \dagger \dagger$ & $0.9(0.3)$ & $1.2(0.3)$ & $1.1(0.4)$ \\
\hline EF (SD), \% & $71(8)$ & $68(6)$ & $66(9)$ & $67(9)$ & $69(8)$ & $68(8)$ & $66(9) \S$ & $71(6)$ \\
\hline LV mass (SD), g & $\begin{array}{c}151(47) \\
\text { t†† }\end{array}$ & $160(43) \dagger †$ & $220(76)$ & $174(67)$ & $189(69)$ & $167(56)$ & $196(67) \S \S$ & $146(46)$ \\
\hline \multirow{2}{*}{$\begin{array}{l}\text { LV ED volume (SD), } \mathrm{ml} \\
\text { LV ES volume (SD), } \mathrm{ml} \\
\text { ED endocardial area (SD), } \mathrm{cm}^{2}\end{array}$} & $108(27)$ & $119(31)$ & $119(29)$ & $126(33)$ & $110(30)$ & $110(21)$ & $120(32)$ & $109(22)$ \\
\hline & $33(17)$ & $39(15)$ & $42(18)$ & $43(20)$ & $35(16)$ & $35(12)$ & $42(19) \S$ & $32(11)$ \\
\hline Base & $15(5)$ & $17(6)$ & $14(6)$ & $17(6)$ & $13(5)$ & $15(5)$ & $14(6)$ & $16(5)$ \\
\hline Mid & $10(3) \dagger$ & $10(4) \dagger$ & $8(3)$ & 11 (3) †† & $8(4)$ & $8(3)$ & $9(4)$ & $10(4)$ \\
\hline Apex & $5(2)$ & $5(3)$ & $4(2)$ & $7(2) \dagger \ddagger$ & $4(2)$ & $3(2)$ & $5(3)$ & $4(2)$ \\
\hline \multicolumn{9}{|l|}{ ED myocardial area (SD), $\mathrm{cm}^{2}$} \\
\hline Base & $26(7)$ & $26(7)$ & $30(9)$ & $28(7)$ & $29(9)$ & $25(7)$ & $29(8) \S$ & $24(7)$ \\
\hline Mid & $24(6) \dagger \dagger \dagger$ & $26(6) \dagger$ & $31(7)$ & $28(7)$ & $28(7)$ & $25(7)$ & $28(7) \S \S$ & $25(6)$ \\
\hline Apex & 18 (6) ††† & $21(5) \dagger \dagger$ & $26(7)$ & $22(6)$ & $22(7)$ & $21(7)$ & $23(6)$ & $20(7)$ \\
\hline$\beta$ Blocker and/or $\mathrm{Ca}$ antagonist (\%) & 95 & 70 & 85 & 96 & 77 & 72 & 77 & 86 \\
\hline
\end{tabular}

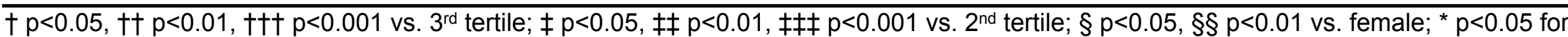
$x^{2}$ 
Table 4: Multivariate regression analyses for predictors of apical LGE, apical MPRi and chest pain

\begin{tabular}{|c|c|c|c|c|}
\hline \multicolumn{5}{|c|}{$\begin{array}{l}\text { Multivariable ordinal logistic regression with apical LGE [none, mild }(<10 \%) \text {, } \\
\text { moderate }(10-20 \%) \text {, severe }(>20 \%) \text { ] as dependent variable in } 76 \text { patients }\end{array}$} \\
\hline Independent variables & OR & $p$ & \multicolumn{2}{|c|}{ 95\% Conf. Interval } \\
\hline Male & 1.88 & 0.193 & 0.73 & 4.87 \\
\hline Age (years) & 1.00 & 0.928 & 0.97 & 1.04 \\
\hline Apical MWT (mm) & 1.21 & 0.008 & 1.05 & 1.39 \\
\hline Contractile persistence (\%CC) & 0.99 & 0.600 & 0.97 & 1.02 \\
\hline MPRi & 0.43 & 0.298 & 0.09 & 2.09 \\
\hline \multicolumn{5}{|c|}{$\begin{array}{c}\text { Multivariable linear regression with apical MPRi as dependent variable in } 76 \\
\text { patients }^{*}\end{array}$} \\
\hline Independent variables & Coef. & $\mathbf{p}$ & \multicolumn{2}{|c|}{ 95\% Conf. Interval } \\
\hline Male & 0.04 & 0.610 & -0.11 & 0.18 \\
\hline Age (years) & -0.002 & 0.467 & -0.01 & 0.003 \\
\hline Apical LGE (\%LV) & -0.001 & 0.245 & -0.01 & 0.004 \\
\hline Apical MWT (mm) & -0.004 & 0.706 & -0.03 & 0.02 \\
\hline Contractile persistence (\%CC) & -0.01 & $<0.001$ & -0.01 & -0.01 \\
\hline \multicolumn{5}{|c|}{$\begin{array}{c}\text { Multivariable logistic regression with chest pain as dependent variable in } 66 \\
\text { patients }\end{array}$} \\
\hline Independent variables & Odds Ratio & $p$ & \multicolumn{2}{|c|}{ 95\% Conf. Interval } \\
\hline Male & 2.66 & 0.159 & 0.68 & 10.42 \\
\hline Age (years) & 1.01 & 0.770 & 0.96 & 1.06 \\
\hline Apical LGE (\%LV) & 1.03 & 0.426 & 0.95 & 1.13 \\
\hline Apical MWT (mm) & 1.02 & 0.858 & 0.82 & 1.27 \\
\hline Contractile persistence (\%CC) & 1.06 & 0.003 & 1.02 & 1.10 \\
\hline
\end{tabular}

* Constant for linear regression model: $1.58, \mathrm{R}^{2}: 0.31$

** 10 patients with missing chest pain data were not included 

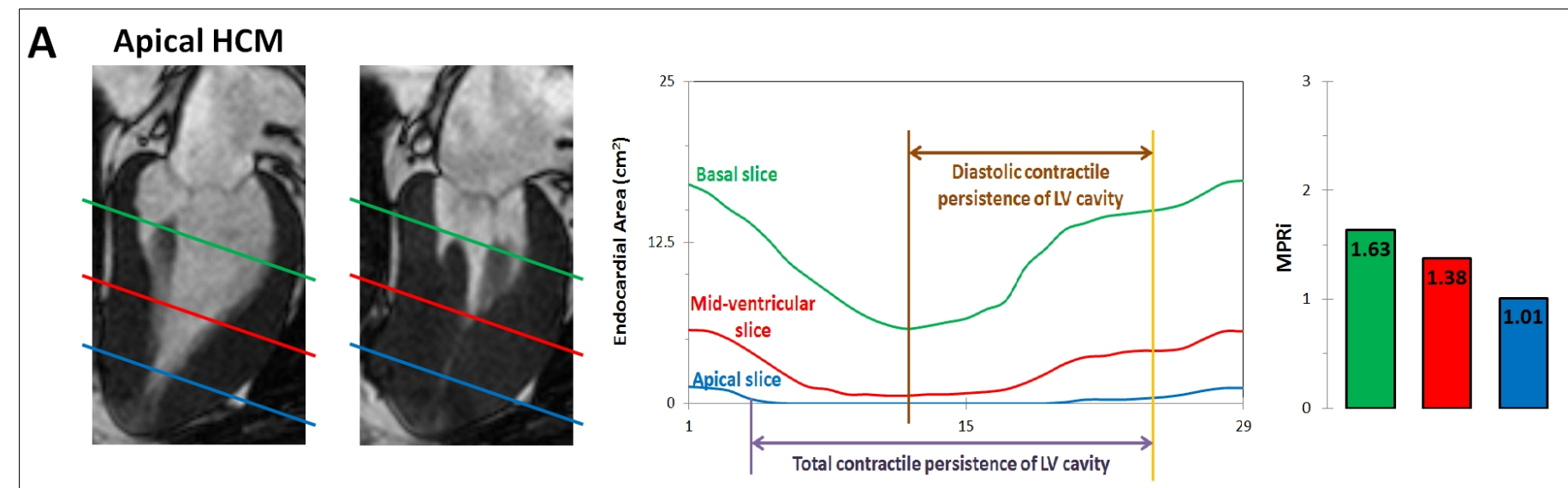

B Control-HCM
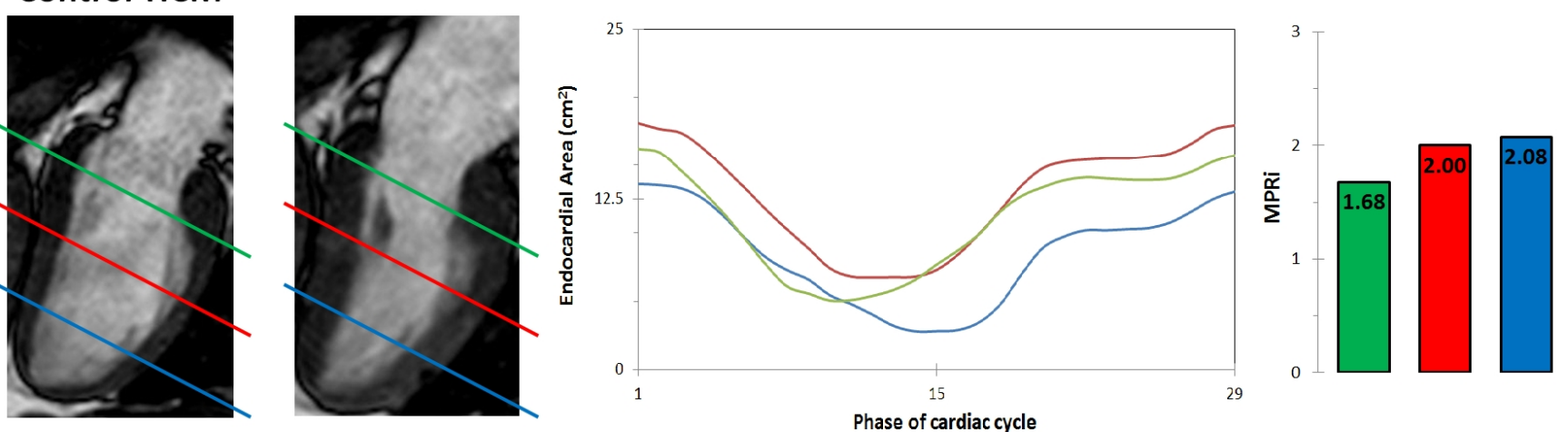

C Normal Control
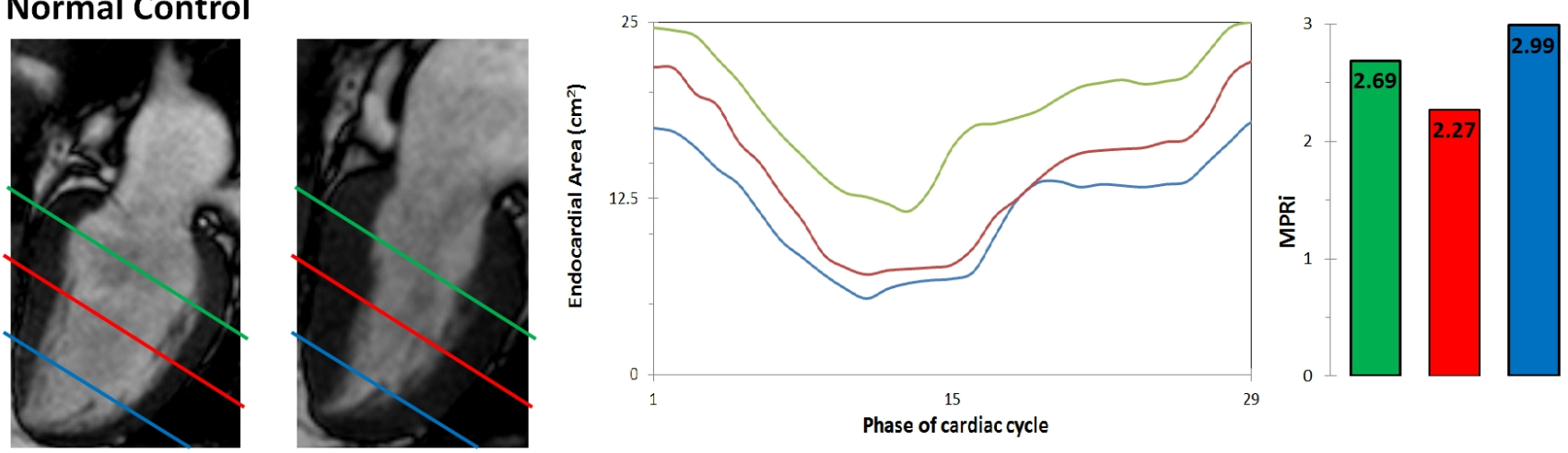

Phase of cordicacte 